\title{
Dilemmas of participation in everyday life in early rheumatoid arthritis: a qualitative interview study (The Swedish TIRA Project)
}

\author{
Annette Sverker, Gunnel Östlund, Mikael Thyberg, Ingrid Thyberg, Eva Valtersson and \\ Mathilda Björk
}

\section{Linköping University Post Print}

\section{Tweet}

N.B.: When citing this work, cite the original article.

Original Publication:

Annette Sverker, Gunnel Östlund, Mikael Thyberg, Ingrid Thyberg, Eva Valtersson and Mathilda Björk, Dilemmas of participation in everyday life in early rheumatoid arthritis: a qualitative interview study (The Swedish TIRA Project), 2015, Disability and rehabilitation, (37), 14-15, 1251-1259.

http://dx.doi.org/10.3109/09638288.2014.961658

Copyright: Informa Healthcare

http://informahealthcare.com/

Postprint available at: Linköping University Electronic Press

http://urn.kb.se/resolve?urn=urn:nbn:se:liu:diva-113134 
Title page

Dilemmas of participation in everyday life in early rheumatoid arthritis. A qualitative interview study (The Swedish TIRA Project).

Annette Sverker $\mathrm{PhD}^{1,2}$ Gunnel Östlund $\mathrm{PhD}^{3}$ Mikael Thyberg $\mathrm{PhD}^{4}$ Ingrid Thyberg $\mathrm{PhD}^{5}$, Eva Valtersson ${ }^{1}$, Mathilda Björk $\mathrm{PhD}^{6,7}$

${ }^{1}$ Rehabilitation section NSC, County Council of Östergötland, Sweden,

${ }^{2}$ Department of Social and Welfare Studies, Linköping University, Sweden

${ }^{3}$ Department of Social Work, School of Health Care and Social Welfare, Mälardalen University, Sweden.

${ }^{4}$ Department of Pain and Rehabilitation Center and Department of Medical and Health Sciences, Linköping University, SE-581 85 Linköping, Sweden

${ }^{5}$ Department of Rheumatology and Department of Clinical and Experimental Medicine, Linköping University, Linköping, Sweden.

${ }^{6}$ Rehabilitation section HMC, County Council of Östergötland, Sweden,

${ }^{7}$ Rehabilitation Center and Department of Clinical and Experimental Medicine, Linköping University, Linköping, Sweden.

Short title: Everyday dilemmas in RA

Key words: activity limitations, patient perspective, critical incident technique, rehabilitation

\section{Corresponding author:}

Mathilda Björk, PhD

Rehabilitation Section HMC

County Council of Östergötland

58185 Linköping, Sweden

mathilda.bjork@liu.se

+46703328475 
Purpose: To explore the experiences of today's patients with early RA with respect to dilemmas of everyday life, especially regarding patterns of participation restrictions in valued life activities.

Method: 48 patients, aged $20-63$, three years post RA diagnosis were interviewed using Critical Incident Technique. Transcribed interviews were condensed into meaningful units describing actions/situations. These descriptions were linked to ICF participation codes according to ICF linking rules.

Results: Dilemmas in everyday life were experienced in domestic life, interpersonal interactions and relationships, community, social and civic life. Most dilemmas were experienced in domestic life including participation restrictions in for example gardening, repairing houses, shovelling snow, watering pot plants, sewing, or walking the dog. Also many dilemmas were experienced related to recreation and leisure within the domain community, social and civic life. The different dilemmas were often related to each other. For instance dilemmas related to community life were combined with dilemmas within mobility such as lifting and carrying objects.

Conclusions: Participation restrictions in today's RA patients are complex. Our results underline that the health care needs to be aware of the patients' own preferences and goals to support the early multi professional interventions in clinical practice. 
Rheumatoid arthritis (RA) is a chronic inflammatory disease often associated with disability [1-3]. Because the disease mechanisms are now fairly well known, today's strategy of early pharmacological treatment and new biological drugs have lead to reduced disease activity and less disability compared to previously [4,5]. However, even in early RA many patients still report disability, implying a persistent need for rehabilitative interventions and medication, and probably also improvements of clinical reasoning with respect to rehabilitation strategies $[3,6,7]$. In comparison with the greatly developed knowledge of biological aspects of the disease, it is necessary to learn more about patients' perspectives of disabling mechanisms in order to improve the rehabilitation part of clinical interventions. Previous research has highlighted patients' perspectives and has resulted in recommendations in using the perspectives of those who experience the disease. Maintaining social roles and the ability to participate in society are important for RA patients [8,9], and are significantly linked to health and wellbeing [10]. However, patients with RA report that they need to struggle to find a balance in their activity pattern [11], and in order to be able to participate they sometimes need to overdo activities causing impairments and negative feelings [8].

Though it is known that even basic daily activities are affected in today's patients with early RA [3] and that more complex aspects, so-called valued life activities, are important for the psychological well-being of populations with long term RA [12], there is a clinical need to explore the patterns of disability in more detail in order to support the early intervention strategy of today [13]. One problem is that studies on these issues refer to quite different underlying theories and terminologies. For example, the terminologies of the Health Assessment Questionnaire (HAQ) [3], the Valued Life Activities (VLA) instrument [12], qualitative reports on the patients' own perspectives [13] and studies relating to the International Classification of Functioning, Disability and Health (ICF) [14] differ quite a lot. 
One way of developing professional and interdisciplinary knowledge on the basis of the patients' perspectives is to use open qualitative interviews and to interpret the results in terms of the ICF [13]. A previous study [13] using such a strategy on participation in work in early RA highlighted the problem of prioritizing between remunerative work and other so-called valued life activities that are important for psychological well-being . Also, the patients' descriptions of work related dilemmas included descriptions of specific problems with embedded activities such as walking, lifting and managing one's activity level. In this context, "embedded" means that remunerative work was performed by, for example, walking and that problems related to walking were experienced as a disabling mechanism with respect to participation in work. Professional awareness about such patterns of disability was interpreted to be important for appropriate early clinical assessments and interventions.

Although the interaction between bodily and environmental aspects is generally recognized in disability theory [15], the ICF tripartite concept of disability (1. Bodily impairments 2. Activity limitations and 3. Participation restrictions) is disputed and difficult to use properly in interdisciplinary research [16-18]. The underlying theory of the ICF tripartite concept of disability is not explicit [19] and the logic of the ICF distinction between activities and participation has been questioned from a philosophical perspective referring to action theory [16]. According to such a philosophical perspective, the tripartite ICF concept of disability does not seem to make sense and might be due to a confusion of the conceptual issue of defining disability and methodological issues related to the need to specify environmental factors with respect to estimations of ability. However, the language of the ICF classification part is somewhat less complicated to use because activities and participation are described in a common list and researchers may focus on the participation aspect $[13,14,20]$. Participation refers to functioning in the actual environment of the studied persons in contrast to the ICF 
concept of activities, which refer to a so-called standard environment or assumptions about such an environment [14]. With exception for a possibility to describe activity/participation aspects at different levels of detail, the underlying theory of the structure of the list of activity/participation concepts is not explicit in the ICF. However, both within and between the nine chapters, the activity/participation categories are approximately arranged in an order from what seems to represent quite basic actions such as lifting to more complex action sequences or action chains such as remunerative employment [16]. In Annex 3 of the ICF, researchers are suggested to use the categories in different ways depending on the orientation of the research [14]. The aim of this study was to explore the experiences of today's patients with early RA with respect to dilemmas of everyday life, especially regarding patterns of participation restrictions in valued life activities.

\section{MATERIALS AND METHOD}

\section{Design}

Critical Incident Technique (CIT) was used for data collection. CIT is a flexible qualitative research method by which observations of human behaviour in defined situations can be collected. It captures, in a structured way, the qualities of perceived dilemmas and experiences [21]. The method is sensitive to most of the individual's important problems $[21,22]$ and it has been applied in patients with different medical conditions [23-27]. Data were collected through semi-structured interviews to enable patients to describe, in their own words, their experiences of everyday life dilemmas related to RA.

\section{Informants}


This study is associated with the prospective multi-centre early arthritis project with the Swedish acronym TIRA-2 [3]. The purpose of TIRA-2 was to establish routines for early diagnosis and intervention, and to collect research data. Patients in the present study were recruited from the 522 patients included in the TIRA-2 cohort during 2006-2009. Information pertaining to genetics, disease activity, disability and on going disease modifying anti-rheumatic drugs were registered at inclusion, at 3, 6 and 12 months after inclusion and thereafter yearly. Patients were offered pharmacological treatment, physiotherapy, occupational therapy and social counselling on an individual schedule depending on individual needs during the study period. Disease activity was assessed according to the 28-joint count disease activity score (DAS28) [28]. Disability was reported using the Swedish version of the Health Assessment Questionnaire (HAQ) [29].

The inclusion criteria for this study were persons aged between 20-63 years who had recently reached 3 years post-diagnosis. Participation recruitment began in 2009 from patients included in TIRA-2 during 2006. Of these 128 patients 53 were under 64 years at time for inclusion. These 53 patients that fulfilled the present study's criteria were invited to participate in the present study by letter. They received information about the aim of the study, that their participation would be voluntary and that they could withdraw at any time without affecting their medical treatment. Two weeks after they received the introductory letter, the patients were contacted by telephone and asked about volunteering for the study. For those who agreed to participate, a time and place for the interview was then decided. Eleven patients declined leaving 42 patients. The 11 patients, eight women and three men, declined to participate due to lack of time, no daily life dilemmas as a result of RA or lack of interest. Further, the first six patients from TIRA-2 who reached 3 years post-diagnosis in 2010 were asked to volunteer. All these patients agreed to participate giving a total of 48 
patients in the study group.

The patients' 3-year follow-up scores tested during the TIRA-2 project exhibited a median disease activity score of 2.4 (min-max, 0-6), and a median HAQ score of 0.25 (min-max, 02). University education was more frequent in women than in men and the majority of the patients were employed (Table 1). At the 3-year follow-up, Disease-modifying antirheumatic drugs (DMARDs) were prescribed to $88 \%$ of the patients.

-Insert table 1 about here

\section{Data collection.}

The interviews were performed by the first, second and fourth authors (AS, GÖ, EV) who were not involved in the clinical treatment of the patients. A confidential interview location was chosen by each of the informants, either at home, the workplace, at the hospital or university. The interview questions were first pilot tested on five patients with RA to evaluate their functionality and to test the interview procedure. After the pilot testing minor changes to the questions were made.

During data collection, all interviews started with the following central questions: can you describe how your everyday life works? Can you describe an occasion in your everyday life, preferably during the last week, when you were hindered by or reminded of your RA? Follow-up questions allowed the patients to describe more about their situation or dilemma and the consequences of their dilemma (the interview guide is available upon request). Interviews lasted between 45 and 90 min, were digitally recorded with the patient's 
permission, and transcribed verbatim. The data collection period was between October 2009 and May 2010.

The study was approved by the Research Ethics Committee of the Faculty of Health Sciences, Linkoping University, no. M168-05 T84-09, Sweden. Informed consent was given by the participants.

\section{Data analysis}

The objective of the data analysis was to provide a detailed, comprehensive and valid description of the dilemmas studied [22]. The data analysis process, as described below, was performed independently by each interviewer (AS, GÖ, and EV), two social workers and one occupational therapist, who analysed the transcribed version of their own interviews. Initially, each interview was read several times in order for the author to become familiar with the data and to obtain a sense of the whole. The transcribed interviews were read horizontally (the whole interview of an individual patient) to achieve contextual information. In the subsequent data condensation, descriptions of dilemmas were marked and abstracted from the text. In parallel with repeated re-readings of both the abstracted parts and the whole text, each dilemma was then listed in tabular form, describing the reported situation and actions in a condensed form but still using the words of the patient. After the independent analysis, the interviewers undertook extensive discussion in order to reach consensus on the condensed form of the data. 
In the next step, each description of a dilemma was linked to an ICF activity/participation code, by two authors (EV and MT), one occupational therapist and one specialist in rehabilitation medicine, according to the updated ICF linking rules [30]. According to the linking rules, a dilemma could be assigned one or several codes depending on the concepts included in the description. The authors first performed the coding independently. The results were then compared, and diverging results at different levels of coding were checked against the linking rules then discussed until an agreement was obtained.

The ICF activity/participation categories with corresponding alphanumerical codes are divided into domains. Each domain is assigned a chapter that contains several categories [14]. After the ICF activity/participation coding, all dilemmas were sorted and listed in rank order from the highest ICF chapter number, downwards. For dilemmas with several ICF codes, the authors chose to set the highest ICF chapter number as the main concept, e.g. p920 is higher than p530, with other concepts of the same dilemma as an "embedded categories" in a context of the former activity/participation category [13]. In this study, descriptions of a dilemma which was not linked to any code representing the domains of Self-care (Chapter 5), Domestic life, (Chapter 6) Interpersonal interactions and relationships (Chapter 7) or Community, social and civic life (Chapter 9), i.e. not linked to what would approximately correspond to the mentioned so-called valued life activities, were not included on their own in the further analysis. However, descriptions linked to an ICF domain with a lower chapter number, such as mobility (Chapter 4), were included, as an embedded category when the description of a dilemma contained words that were linked to a domain with a higher chapter number, such as Self-care. Dilemmas that were linked to so-called major life areas, e.g. ICF Chapter 8, were analysed separately in a study on work-related participation restrictions [13]. 


\section{Terminology and underlying theory}

In this study, we try to use the language of the ICF as far as possible, but at the same time pay attention to the described interdisciplinary problem that the middle part of the tripartite ICF concept of disability, i.e. "activity limitations" in an individual perspective, does not tally with the basic structure of bipartite social models that, in terms of the ICF, just make a distinction between bodily impairments and participation restrictions in a social perspective [15]. In line with this, we endorse the mentioned philosophical perspective referring to action theory [16]. In this study, the term activities is used simply to denote the whole activity/participation list of things that people may do and the term participation is used to denote actually performed activities with respect to the whole ICF activity/participation list $[13,20]$. In terms of occupational therapy theory, this usage refers to the more abstract meaning of activity as form in contrast to activity as action [31]. According to this terminology, we use expressions such as daily activities, valued life activities and participation in leisure activities without referring to the ICF concept of "activities" in an individual perspective and without referring to a so-called standard environment. Actually performed activities in more or less standardized environments are simply included in the concept of participation and a social perspective. Correspondingly, the prefix $\mathrm{p}$ for participation is used in alphanumerical codes of the ICF activity/participation list [14], which are attributed to the described experiences of the interviewed patients.

\section{RESULTS}

A wide range of categories related to participation dilemmas were identified and interpreted 
in terms of the ICF domains Self-care, Domestic life, Interpersonal interactions and relationships and Community, social and civic life. Table 3 shows all categories within each of these domains, the number of dilemmas, short descriptions covering all reported dilemmas, and the ICF codes for the embedded categories. The embedded categories give more information as to what the dilemma is about, since they contain categories from other participation-related domains.

The categories with the most dilemmas within each domain are commented on below. The ICF two-level description (three digits) is generally used. In some cases, the detailed description with four digits is used to clarify the presentation.

\section{Self-care}

Experienced dilemmas within the Self-care domain included the ICF categories washing oneself, caring for body parts, toileting, dressing, eating, drinking, and looking after one's health. Descriptions of all dilemmas in these categories are shown in table 3.

The category looking after one's health (p570) contained most dilemmas in the Self-care domain and related to managing diet and fitness (p5701) and maintaining one's health (p5702). Reported dilemmas in this category were about handling medical side effects, how to plan medical intake and worries about gaining weight when physical exercise was problematic. One man reported poor sleep when taking Metoject and did not plan any meetings with customers the day after the injection; this dilemma included the embedded category carrying out daily routine (p230/p2303 managing one's own activity level). Some patients reported worries about gaining weight when walking (p450) was difficult. One woman was afraid of having her medicines confiscated at the customs control when travelling abroad (p470). 
Many dilemmas within the Self-care domain were also related to dressing (p540), putting on clothes (p5400), putting on footwear (p5402) and choosing appropriate clothing (p5404). Patients reported dilemmas about having to get up earlier in the morning and wait for the body to limber up before dressing, having problems putting on shoes or wearing high-heeled shoes when their feet were swollen or in pain, using zippers and buttons, tying shoelaces, putting on heavy jackets or wearing rings and watches. In some of these dressing dilemmas, embedded activities from the mobility domain were involved, exemplified by difficulties with changing body position (p410) when bending down to dress, fine hand use (p440) when buttoning and using zippers. Wearing shoes with high heels had walking (p450) as an embedded category. Dilemmas where morning stiffness gave dressing problems and delayed morning activities had the embedded category carrying out daily routine (p230/p2303 managing one's own activity level).

\section{Domestic life}

Dilemmas within the domain Domestic life included the categories acquisition of goods and services, preparing meals, doing housework, caring for household objects, and assisting others. Descriptions of all dilemmas in these categories are shown in table 3.

The highest number of dilemmas within the domain Domestic life was included in the category caring for household objects (p650). The dilemmas related to making and repairing clothes (p6500), maintaining dwellings and furnishings (p6501), maintaining vehicles (p6503), taking care of plants (p6505), and taking care of animals (p6506). Patients reported dilemmas while sewing, repairing houses indoors and outdoors, shovelling snow, assembling or moving furniture, changing the exhaust pipe on the car, gardening, watering pot plants, 
walking the dog, and taking care of horses. One woman reported problems while sewing and repairing trousers and the dilemma was explained by the embedded ICF category fine hand use (p440). While laying a floor, a man had to adapt the amount of exertion used and the dilemma had the embedded category carrying out daily routine (p230/p2303 managing one's own activity level). One reported dilemma about assembling furniture on the floor was related to maintaining a body position ( $\mathrm{p} 415)$; this caused the patient foot pain, which lasted for two days after being in a squatting position. Gardening dilemmas, such as weeding, were about changing basic body position (p410), when squatting or kneeling. Caring for animals such as dogs and horses exhibited dilemmas related to hand and arm use (p445), walking (p450) or lifting and carrying objects (p430), such as carrying buckets of water to the horses. Dilemmas when walking the dog were mainly related to foot problems and walking (p450), and patients having to choose sturdy shoes (p540) and smooth walking paths.

Many reported dilemmas in the domain Domestic life were included in the category doing housework (p640). The dilemmas related to washing and drying clothes and garments (p6400), cleaning living area (p6402) and using household appliances (p6403). Patients reported dilemmas related to laundry care, washing up, cleaning, cleaning windows, hanging curtains, vacuuming and ironing. One woman indicated that she was too tired to manage the laundry during the week, and another woman had to take breaks while washing up. These two dilemmas included the embedded category carrying out daily routine (p230/p2303 managing one's own activity level). Embedded mobility terms for dilemmas in the category doing housework were the same as within the category caring for household objects, except for moving around (p455), exemplified by a patient having problems climbing the stairs to get to the laundry room. 
Dilemmas within the category acquisition of goods and services (p620) were related to shopping (p6200) and gathering daily necessities (p6201). Patients reported problems when queuing in shops due to difficulties standing still. This dilemma was thus explained by the embedded ICF-category maintaining a body position (p415). One woman described tiredness when being in crowded shops and tried to avoid them - the dilemma was connected to carrying out daily routine (p230/ p2303 managing one's own activity level). The shopping dilemmas were mainly described as problems with lifting and carrying objects (p430), hand and arm use (p445), fine hand use (p440) and moving around in different locations (p460). One man described a dilemma with chopping wood and carrying the firewood indoors, which contained the embedded category hand and arm use (p445). Another man reported difficulties walking (p450) in the forest when going to cut down trees to make his own firewood.

\section{Interpersonal interactions and relationships}

Within the domain Interpersonal interactions and relationships, experienced dilemmas in terms of the ICF included basic interpersonal interactions, complex interpersonal interactions, relating with strangers, informal social relationships, family relationships and intimate relationships. Descriptions of all dilemmas in these categories are shown in table 3.

The category family relationships (p760) included most dilemmas within this domain. The dilemmas were related to parent-child relationships (p7600), sibling relationships (p7602) and extended family relationships (p7603). Some reported dilemmas were about avoiding visiting family members, such as a mother not seeing her daughter when she felt unable to help with chores that had to be done at her farm. Many dilemmas referred to grandchildren. 
One patient could not offer to drive their grandchildren due to difficulties driving the car (p475). In situations when playing with grandchildren, patients described difficulties in being on the floor, such as changing or maintaining body positions (p410, p415), lifting and carrying objects (p430) and moving around (p455). Difficulties kicking a ball with a grandchild included the embedded category moving objects with lower extremities (d435). A grandmother described her grandchildren laughing at her when she wet herself while having difficulty getting out of bed. This dilemma was connected to the embedded category toileting (p530). Grandchildren were also involved in dilemmas such as having problems lifting a grandchild onto a bicycle seat when collecting them from day care, or a father having difficulties lifting his bullied daughter when he needed to comfort her. These two dilemmas were connected with the embedded ICF-categories assisting others (p660) and lifting and carrying objects (p430). Some patients reported that time spent with the family had been reduced due to fatigue, and these dilemmas had the embedded category carrying out daily routine (p230/p2303 managing one's own activity level).

Dilemmas in the category intimate relationships (p770) related to spousal relationships (p7701) and sexual relationships (p7702). Patients reported dilemmas about embracing, separation due to the patient's spouse not accepting the disease, and dilemmas in their sex life. One woman felt insufficient and dependent on her husband when she could not help enough with repairing their dwelling (p650) due to reduced hand and arm use (p445). When hugging their spouse was problematic, the embedded category physical contact in relationships (p7105) was added and thus the dilemma was described by two categories within the same domain. Sex life dilemmas were exemplified by a young woman's problem of feeling "unsexy" when having pain in her whole body. 


\section{Community, social and civic life}

Within the domain Community, social and civic life, described dilemmas included community life, recreation and leisure, and religion and spirituality. Descriptions of all dilemmas in these categories are shown in table 3.

Most dilemmas in this domain were reported in the category recreation and leisure (p920), and related to play (p9200), sports (p9201), arts and culture (p9202) and socializing (p9205). About half of the reported dilemmas were linked to the ICF categories at a three-digit level when the dilemmas did not fit into the description of the detailed four-digit level categories. Some recreation and leisure dilemmas concerned the patient's choice to refrain from leisure activities due to RA e.g. sport fishing, gymnastics, running races, playing football or dancing. Patients also had, in some cases, replaced demanding physical activities with less demanding activities, e.g. bicycling with friends instead of walking together. Some patients had continued to participate in their activities of interest but had been forced to adjust how they performed them, or performed them in the same way as previously, and accepted the pain. Examples of recreation and leisure activities where reported dilemmas were analysed as having embedded ICF categories are presented below.

Several patients reported they had reduced time available for recreation and leisure due to fatigue after work. They needed to go to bed earlier and this also affected their relationships with friends or workmates. These types of dilemmas had the embedded categories carrying out daily routine (p230/p2303 managing one's own activity level) and informal social relationships (p750). A woman described a raised stress level when being in a noisy environment on a cruise, and the dilemma had the embedded ICF category handling stress 
and other psychological demands (p240). When a patient described difficulties performing movements in an Afro dance class, the dilemma was attributed the embedded category changing body position (p410). A reported dilemma when watching show jumping concerned difficulties in sitting and standing for too long and was related to the embedded ICF category maintaining a body position (p415). Problems with spending long periods of sitting during a coach holiday were presented by a female patient. The embedded category using transportation ( $\mathrm{p} 470$ ) was added to her dilemma. Described dilemmas, such as difficulties tying lines to fishing lures, making flower arrangements, or fingers not keeping pace when playing the trumpet, were related to the embedded category fine hand use (p440). When going riding, a woman described problems with tightening the girths while saddling the horse and in this dilemma the embedded category was hand and arm use (p445). Another woman reported difficulties getting up and down from a horse, which was related to the embedded category moving around (p455). On the golf course, a man could not keep pace with his friends (embedded category: walking p450) when the terrain was hilly. Some dilemmas were connected to the embedded category dressing (p540), exemplified by problems wearing ski boots. Dilemmas about going downhill skiing had the embedded category moving around using equipment (p465). Some women described their reduced physical training and related this to problems with weight gain. The embedded category looking after one's health (p570) was added to these dilemmas. Some leisure activities concerned caring for dogs, such as agility training, and the embedded category caring for household objects (p650) were included. Changes in ability to perform leisure activities in RA patients also affected relationships, exemplified by one woman who missed her husband's companionship (intimate relationships p770) when she could no longer join him in catching crayfish or hunting. 
Dilemmas related to the category community life (p910) related to informal associations (d9100) and ceremonies (p9102). Patients reported dilemmas when performing voluntary tasks, and dilemmas about having to reduce their engagement in civil society. A young man who was a materials manager in a football club described problems handling balls with his hands and legs, picking bottles and carrying heavy material. The embedded ICF categories lifting and carrying objects (p430) and moving objects with lower extremities (p435) were added to this dilemma. One patient reported problems with fine hand use (p440) while filing and doing paperwork in an Athletic Association. Another man had stopped working for the Lions Club NGO when he did not have the energy left to engage others. This dilemma was attributed the embedded categories carrying out daily routine (p230) and informal social relationships ( $\mathrm{p} 750)$. A woman reported problems with preparing meals in an organisation due to pain (embedded category: preparing meals p630). She endured cooking because she appreciated the social life the organisation brought her. Another dilemma was about ceremonies. A man described that he refrained from attending a wedding due to fear of shaking hands with people. This dilemma was related to the embedded ICF category basic interpersonal interactions (p710/p7105 physical contact in relationships).

-insert table 3 about here

\section{DISCUSSION}

A wide spectrum of participation dilemmas in everyday life was described already three years after RA diagnosis in our cohort that represented the early pharmacological intervention strategy of today. Patients reported detailed dilemmas and complex patterns of embedded categories indicating possible disabling mechanisms, which could be important for clinical 
reasoning regarding complementary interventions. Although the qualitative design of this study does not permit conclusions regarding the actual frequency of dilemmas in early RA populations, dilemmas in the category recreation and leisure were most frequently mentioned.

The impact of RA on participation as experienced by the patients in this study is supported by earlier research [32-35]. Even though today's patients undergo early interventions, including biological medication and multi-professional treatment, RA still affects all aspects of life [6]. The patients in our study experienced dilemmas related to participation in everyday life, which were represented by the ICF domains Self-care, Domestic life, Interpersonal interactions and relationships, and Community, social and civic life.

The ICF has previously been used to describe disability, including participation, in chronic diseases [36-38]. To facilitate the use of ICF, specific core sets have been developed for different conditions in order to provide assessment guidelines in clinical care. The comprehensive ICF core set for RA includes 96 categories, with 32 from activities and participation [39]. The patients in our study experienced dilemmas that were not included in the ICF core sets for RA. For example, the reported dilemmas in the ICF domain Interpersonal interactions and relationships (Chapter 7) are associated with six out of the seven categories contained in that chapter. According to Geuskens et al [33], participation restrictions in RA are often caused by a reduction in fulfilling social roles. In the present study, dilemmas linked to participation in Interpersonal interactions were often mentioned. The ICF core set for RA includes only two of the seven categories from Chapter 7: family relationships (d760) and intimate relationships (d770). In our rich and multi-faceted descriptions, the patients experienced dilemmas related to relationships when meeting new people, spending time with their family but also by avoiding activities where they needed to 
shake hands with unknown people. The fact that RA causes hindrances in participating in social activities and fulfilling social roles has been described earlier by Feldthusen et al [40] and Ahlstrand et al [8]. It is important to note that the ICF core set for RA does not include caring for household objects (d650), which in this study contained the highest number of dilemmas linked to domestic life. This discrepancy in participation restrictions identified in our study and the content of the ICF RA core set highlights the need for including the patients' preferences and own goals in clinical assessments and interventions.

As well as the ICF core sets, the results of the present study could also be compared with the questions used in the Health Assessment Questionnaire (HAQ) which is commonly used to assess disability in RA. The HAQ is limited to the more basic activities [41] which are found in the ICF activities and participation domains with lower chapter numbers. The HAQ does not include activities concerning, for example, leisure and recreation as the patients in the present study often mentioned. In the results, a large number of dilemmas were related to ICF domains with higher chapter numbers, which are also important to include when assessing disability and in drawing conclusions of a patient's functioning in daily life [42].

In the present study, patients often described decreased participation in leisure and recreational activities, despite that the performance of such activities is highly valued $[10,43,44]$. According to Reinseth et al [45], only $25 \%$ of patients with RA are physically active in their leisure time, and that hindrances for patients with arthritis in participating in recreation and leisure activities include pain [8], fatigue [40], or lack of time [46]. Some patients in this study indicated that they replaced demanding physical activities with less challenging activities, while others described a need to adjust their activities. These strategies are recognized by Squire [47] as a way for patients to take control over their leisure time and 
still be able to perform valued activities. The ability to perform vigorous activities is closely related to higher self-efficacy, lower pain and lower fatigue [45]. The high number of identified dilemmas regarding leisure and recreational activities, and interpersonal interactions emphasizes that even though patients experience a more rewarding leisure time as a result of the new biological medications $[6,35]$, it is clinically relevant to look beyond the domain of self-care [47] and focus on the patient's own experiences of important aspects of participation and participation restrictions.

The experienced dilemmas in daily life situations often included descriptions of other activities interpreted as embedded categories or activities. In the category recreation and leisure, a variety of embedded ICF categories were mentioned such as a range of mobility categories, e.g. moving around, getting up and down from a horse when riding, or fine hand use such as in holding a golf club or playing the trumpet. Daily activities are performed in a complex pattern, unique to the each individual [48]. According to Erlandsson and Eklund [49], the pattern of daily activities is dominated by main actions in combination with other interwoven activities performed at the same time, automatically or not. These interwoven activities are often performed with slightly less attention and might be unconscious at first [50]. However, from a professional perspective they are important in analysing participation restrictions, with respect to the choice of the most adequate interventions.

\section{Method discussion}

The participants were recruited from the well-defined TIRA-2 cohort. The patients included in the TIRA-2 project were diagnosed at specialist clinics and had been prescribed DMARDs based on individual needs since the time of diagnosis. Thereby, our results are applicable to today's patients and early intervention strategy. The results showed that the ICF language 
covers a broad range of aspects that may be used to interpret the experiences of patients with RA. Verbatim examples showed the complexity of participation dilemmas. The CIT technique is a well-established method of data collection and has been included in several studies performed on different patient groups [23-27]. This technique was chosen since it has been proven to be efficient in capturing both minor and major recurrent dilemmas. The validity of the results is supported by the use of researchers representing different professional backgrounds, three researchers involved in interviews and identification of dilemmas and two researchers involved in using the language of the ICF independently of each other in order to interpret the dilemmas.

One limitation was that the study only focused on problematic situations and another limitation was that environmental aspects were not explored in detail. Of course, the qualitative approach may also be regarded as a limitation with respect to knowledge about the actual frequency and severity of the described dilemmas in today's population with early RA and early pharmacological interventions, but that question was not included in the aim of this study [13]. The quantitative disability data that were also obtained from the interviewed patients in order to describe the sample suggest that the patterns of disability that were qualitatively described are not trivial [3]. On the basis of the reported qualitative descriptions it is possible to make quantitative studies of the frequency of different patterns with respect to what basic activities are embedded in problems with different so-called valued life activities $[10,12,51]$. In a clinical perspective, it is important to be aware of the described spectrum of patterns of disability that may be experienced by an individual patient. Such awareness has similarities to clinical experience, but the use of a qualitative method is supposed to provide a more systematic interpretation and organization of knowledge [52]. Thus, the reported interpretations of the patients' experiences of participation restrictions related to valued life 
activities may be useful to both experienced and less experienced rehabilitation practitioners who encounter patients with early RA.

\section{Conclusion}

In our study group recruited from a well-defined early RA cohort diagnosed during 2006 2009, patients reported a wide spectrum of everyday life dilemmas, interpreted in ICF terms of participation restrictions, despite early pharmacological and complementary multi-professional interventions. Our findings highlight clinically relevant details and the complexity of participation restrictions in today's RA patients. Awareness of the described patterns of disability that may be encountered in clinical practices is important in order to meet the needs of individual patients with early RA.

\section{DECLARATION OF INTEREST}

There are no conflicts of interest 


\section{REFERENCES}

[1] Hafstrom I, Bala V, Albertsson K, Forslind K, Svensson B. Joint destruction in early rheumatoid arthritis over 8 years is similar in women and men despite apparently higher disease activity and poorer function in women. Ann Rheum Dis 2011;70:70910.

[2] Hallert E, Bjork M, Dahlstrom O, Skogh T, Thyberg I. Disease activity and disability in women and men with early rheumatoid arthritis: An 8-year follow-up of the Swedish TIRA project. Arthritis Care Res (Hoboken) 2012.

[3] Thyberg I, Dahlstrom O, Bjork M, Arvidsson P, Thyberg M. Potential of the HAQ score as clinical indicator suggesting comprehensive multidisciplinary assessments: the Swedish TIRA cohort 8 years after diagnosis of RA. Clin Rheumatol 2012.

[4] Neovius M, Simard JF, Klareskog L, Askling J. Sick leave and disability pension before and after initiation of antirheumatic therapies in clinical practice. Ann Rheum Dis 2011;70:1407-14.

[5] Björk M, Skogh T, Husberg M, Thyberg I. Reduced Sick leace in today's early RA patients compared to 10 years ago, the Swedish TIRA project. . EULAR. Madrid2013.

[6] Linden C, Bjorklund A. Living with rheumatoid arthritis and experiencing everyday life with TNF-alpha blockers. Scand J Occup Ther 2010;17:326-34.

[7] Birch JT, Jr., Bhattacharya S. Emerging trends in diagnosis and treatment of rheumatoid arthritis. Prim Care 2010;37:779-92, vii.

[8] Ahlstrand I, Bjork M, Thyberg I, Borsbo B, Falkmer T. Pain and daily activities in 
Rheumatoid Arthritis. Disabil Rehabil 2011.

[9] Gignac MA, Cao X. "Should I tell my employer and coworkers I have arthritis?" A longitudinal examination of self-disclosure in the work place. Arthritis Rheum 2009;61:1753-61.

[10] Katz PP, Morris A, Yelin EH. Prevalence and predictors of disability in valued life activities among individuals with rheumatoid arthritis. Ann Rheum Dis 2006;65:7639.

[11] Stamm T, Wright J, Machold K, Sadlo G, Smolen J. Occupational balance of women with rheumatoid arthritis: a qualitative study. Musculoskeletal Care 2004;2:101-12.

[12] Katz PP, Neugebauer A. Does satisfaction with abilities mediate the relationship between the impact of rheumatoid arthritis on valued activities and depressive symptoms? Arthritis Rheum 2001;45:263-9.

[13] Sverker A, Thyberg I, Ostlund G, Waltersson E, Thyberg M. Participation in work in early rheumatoid arthritis: a qualitative interview study interpreted in terms of the ICF. Disabil Rehabil 2014;36:242-9.

[14] World Health Organization. International classification of functioning, disability and health (ICF). Geneva: World Health Organization; 2001.

[15] Bickenbach JE, Chatterji S, Badley EM, Ustun TB. Models of disablement, universalism and the international classification of impairments, disabilities and handicaps. Soc Sci Med 1999;48:1173-87.

[16] Nordenfelt L. Action theory, disability and ICF. Disabil Rehabil 2003;25:1075-9.

[17] Gustavsson A. The role of theory in disability research - springboard or straitjacket? Scand J Disabil Res 2004;6:55-70.

[18] Badley EM. Enhancing the conceptual clarity of the activity and participation components of the International Classification of Functioning, Disability, and Health. 
Soc Sci Med 2008;66:2335-45.

[19] Masala C, Petretto DR. From disablement to enablement: conceptual models of disability in the 20th century. Disabil Rehabil 2008;30:1233-44.

[20] Arvidsson P, Granlund M, Thyberg I, Thyberg M. Important aspects of participation and participation restrictions in people with a mild intellectual disability. Disabil Rehabil 2014;36:1264-72.

[21] Flanagan J. The critical incident technique. Psychol Bull 1954;51:327-58.

[22] Woolsey L. The critical Incident technique: an innovative qualitative method of research. Can J Couns 1986;20:242-54.

[23] Stromberg A, Brostrom A, Dahlstrom U, Fridlund B. Factors influencing patient compliance with therapeutic regimens in chronic heart failure: A critical incident technique analysis. Heart Lung 1999;28:334-41.

[24] Kemppainen JK. The critical incident technique and nursing care quality research. J Adv Nurs 2000;32:1264-71.

[25] Ivarsson B, Larsson S, Sjoberg T. Patients' experiences of support while waiting for cardiac surgery. A critical incident technique analysis. Eur J Cardiovasc Nurs 2004;3:183-91.

[26] Hensing GK, Sverker AM, Leijon GS. Experienced dilemmas of everyday life in chronic neuropathic pain patients--results from a critical incident study. Scand J Caring Sci 2007;21:147-54.

[27] Sverker A, Hensing G, Hallert C. 'Controlled by food'- lived experiences of coeliac disease. J Hum Nutr Diet 2005;18:171-80.

[28] Prevoo ML, van 't Hof MA, Kuper HH, van Leeuwen MA, van de Putte LB, van Riel PL. Modified disease activity scores that include twenty-eight-joint counts. Development and validation in a prospective longitudinal study of patients with rheumatoid arthritis. 
Arthritis Rheum 1995;38:44-8.

[29] Ekdahl C, Eberhardt K, Andersson SI, Svensson B. Assessing disability in patients with rheumatoid arthritis. Use of a Swedish version of the Stanford Health Assessment Questionnaire. Scand J Rheumatol 1988;17:263-71.

[30] Cieza A, Geyh S, Chatterji S, Kostanjsek N, Ustun B, Stucki G. ICF linking rules: an update based on lessons learned. J Rehabil Med 2005;37:212-8.

[31] Reed K, Sanderson S. Concepts of occupational therapy. Philadelphia: Lippincott, Willliams \& Wilkins; 1999.

[32] Burton W, Morrison A, Maclean R, Ruderman E. Systematic review of studies of productivity loss due to rheumatoid arthritis. Occup Med (Lond) 2006;56:18-27.

[33] Geuskens GA, Burdorf A, Hazes JM. Consequences of rheumatoid arthritis for performance of social roles--a literature review. J Rheumatol 2007;34:1248-60.

[34] Kuhlow H, Fransen J, Ewert T, Stucki G, Forster A, Langenegger T, Beat M. Factors explaining limitations in activities and restrictions in participation in rheumatoid arthritis. Eur J Phys Rehabil Med 2010;46:169-77.

[35] Strand V, Khanna D. The impact of rheumatoid arthritis and treatment on patients' lives. Clin Exp Rheumatol 2010;28:S32-40.

[36] Khan F, Amatya B, Ng L. Use of the International Classification of Functioning, Disability and Health to describe patient-reported disability: a comparison of Guillain Barre syndrome with multiple sclerosis in a community cohort. J Rehabil Med 2010;42:708-14.

[37] Khan F, Pallant JF. Use of the International Classification of Functioning, Disability and Health to identify preliminary comprehensive and brief core sets for Guillain Barre syndrome. Disabil Rehabil 2011;33:1306-13.

[38] Kirchberger I, Sinnott A, Charlifue S, Kovindha A, Luthi H, Campbell R, Zwecker M, 
Scheuringer M, Cieza A. Functioning and disability in spinal cord injury from the consumer perspective: an international qualitative study using focus groups and the ICF. Spinal Cord 2010;48:603-13.

[39] Stucki G, Cieza A, Geyh S, Battistella L, Lloyd J, Symmons D, Kostanjsek N, Schouten J. ICF Core Sets for rheumatoid arthritis. J Rehabil Med 2004:87-93.

[40] Feldthusen C, Bjork M, Forsblad-d'Elia H, Mannerkorpi K. Perception, consequences, communication, and strategies for handling fatigue in persons with rheumatoid arthritis of working age-a focus group study. Clin Rheumatol 2013.

[41] Katz P, Morris A, Yelin E. Subclinical disability in valued life activities among individuals with rheumatoid arthritis. Arthritis Rheum 2008;59:1416-23.

[42] Wilkie R, Jordan JL, Muller S, Nicholls E, Healey EL, van der Windt DA. Measures of social function and participation in musculoskeletal populations: Impact on Participation and Autonomy (IPA), Keele Assessment of Participation (KAP), Participation Measure for Post-Acute Care (PM-PAC), Participation Objective, Participation Subjective (POPS), Rating of Perceived Participation (ROPP), and The Participation Scale. Arthritis Care Res (Hoboken) 2011;63 Suppl 11:S325-36.

[43] Ahlmen M, Nordenskiold U, Archenholtz B, Thyberg I, Ronnqvist R, Linden L, Andersson AK, Mannerkorpi K. Rheumatology outcomes: the patient's perspective. A multicentre focus group interview study of Swedish rheumatoid arthritis patients. Rheumatology (Oxford) 2005;44:105-10.

[44] Lee EO, Kim JI, Davis AH, Kim I. Effects of regular exercise on pain, fatigue, and disability in patients with rheumatoid arthritis. Fam Community Health 2006;29:3207.

[45] Reinseth L, Uhlig T, Kjeken I, Koksvik HS, Skomsvoll JF, Espnes GA. Performance in leisure-time physical activities and self-efficacy in females with rheumatoid arthritis. 
Scand J Occup Ther 2011;18:210-8.

[46] Wikstrom I, Book C, Jacobsson LT. Difficulties in performing leisure activities among persons with newly diagnosed rheumatoid arthritis: A prospective, controlled study. Rheumatology (Oxford) 2006;45:1162-6.

[47] Squire R. Living well with rheumatoid arthritis. Musculoskeletal Care 2012;10:127-34. [48] Polatajko HJ, Davis JA, Hobson SJ, Landry JE, Mandich A, Street SL, Whippey E, Yee S. Meeting the responsibility that comes with the privilege: introducing a taxonomic code for understanding occupation. Can J Occup Ther 2004;71:261-8.

[49] Erlandsson LK, Eklund M. Women's experiences of hassles and uplifts in their everyday patterns of occupations. Occup Ther Int 2003;10:95-114.

[50] Erlandsson LK, Björkelund C, Lissner L, Håkansson C. Women's perceived frequency of disturbing interruptions and its relationship to self-rated health and satisfaction with life as a whole. Stress and health 2009;26:225-32.

[51] Katz PP, Radvanski DC, Allen D, Buyske S, Schiff S, Nadkarni A, Rosenblatt L, Maclean R, Hassett AL. Development and validation of a short form of the valued life activities disability questionnaire for rheumatoid arthritis. Arthritis Care Res (Hoboken) 2011;63:1664-71.

[52] Patton M. Qualitative research \& evaluation methods. Thousand Oaks, CA: Sage Publications.; 2002. 
Table 1 Socio-demographic characteristics of the 48 informants included in the study

Characteristics of the

Women Men

Study population

$34(71 \%) \quad 14(29 \%)$

\section{Age (years)}

20-45

$8+1$

46-55

8

3

56-60

$11 \quad 7$

61-63

7

\section{Education}

Elementary and occupational school

$10 \quad 7$

Upper secondary 2-years

54

Upper secondary 3-years

7

2

University

\section{Employment status}

Full-time work

149

Part-time work

12

9

Unemployed or sick-listed

2

Temporary disability pension/

Early retirement benefit

6

1

Old-age pension

1

DAS28=Disease Activity Score; HAQ=Health Assessment Questionnaire; md=median; iqr; inter quartile range 


\begin{tabular}{|c|c|c|c|}
\hline Quotes about dilemmas experienced in everyday life in early RA & Condensed quotes for linking to ICF participation categories & ICF domain & ICF participation categories \\
\hline $\begin{array}{l}\text { ”I was very active ... exercised four, five times per week ... then when } \\
\text { this came it was boom! nothing! and I'm still there... I did three hours } \\
\text { every night, now it's at best half an hour } \ldots \text {.. I've gained } 10 \text { kilos.” } \\
\text { (Man, } 58 \text { year old, } 3 \text { years post diagnosis) }\end{array}$ & $\begin{array}{l}\text { Has less energy for physical activity than previously. Exercises less. } \\
\text { Weight gain. }\end{array}$ & Self-Care & $\begin{array}{l}\text { p570 looking after one's health } \\
\text { (p5701 managing diet and } \\
\text { fitness) }\end{array}$ \\
\hline $\begin{array}{l}\text { "I laid a } 15-20 \text { square metre floor... I was under time pressure ... felt ... } \\
\text { this isn't good but I have to finish ... I suffered for an entire week } \\
\text { afterwards... I had no energy left... I was just in pain...” } \\
\text { (Man, } 52 \text { years old, } 3 \text { years post diagnosis) }\end{array}$ & Laid floor under time pressure. & Domestic life & $\begin{array}{l}\text { p650 caring for household } \\
\text { objects } \\
\text { (p6501 maintaining dwelling } \\
\text { and furnishings) }\end{array}$ \\
\hline $\begin{array}{l}\text { "... I feel really unsexy as I can hardly walk... my hands aren’t } \\
\text { especially beautiful, they have bumps... have problems with my knee... } \\
\text { shoulders and everything ... sometimes I have pain in my whole body } \\
\ldots \text { it affects me, especially psychologically ... one wonders ... is this } \\
\text { going to continue... will he [the boyfriend] accept me then because sex } \\
\text { is a big part of a relationship ..." } \\
\text { (Woman, } 22 \text { years old, } 3 \text { years post diagnosis) }\end{array}$ & $\begin{array}{l}\text { Unsexy, hands with bumps, pain in knee and shoulders, whole body. } \\
\text { Will her boyfriend accept her? }\end{array}$ & $\begin{array}{l}\text { Interpersonal interactions and } \\
\text { relationships }\end{array}$ & $\begin{array}{l}\text { p770 intimate relationships } \\
\text { (p7702 sexual relationships) }\end{array}$ \\
\hline $\begin{array}{l}\text {...”I stopped riding... couldn't saddle up, couldn't tighten the girth ... I } \\
\text { was too bad, quite simply, I couldn't do it, and that makes me really sad } \\
\text { (Woman, } 52 \text { years old, } 3 \text { years post diagnosis) }\end{array}$ & Stopped riding. Couldn't saddle the horse, couldn't tighten the girth.. & Community, social and civic life & $\begin{array}{l}\text { p920recreation and leisure } \\
\text { (p9201sports) }\end{array}$ \\
\hline
\end{tabular}


Table 3: Dilemmas concerning Self-care, Domestic life, Interpersonal interactions and relationships and Community, social and civic life.

\begin{tabular}{|c|c|c|c|c|}
\hline \multicolumn{2}{|c|}{ ICF category } & No of dilemmas & Description of experienced dilemmas & Embedded ICF activity/participation \\
\hline \multicolumn{5}{|c|}{ Domain 5: Self-care } \\
\hline p510 & Washing oneself & 5 & Showering/bathing, washing hair & $\mathrm{p} 445$ \\
\hline p520 & Caring for body parts & 6 & Brushing teeth or dental prosthesis, combing hair, caring for nails & $\mathrm{p} 445$ \\
\hline p530 & Toileting & 4 & Getting to the toilet in time, buttoning clothes, wiping one's butt & $\mathrm{p} 410$ \\
\hline p540 & Dressing & 13 & $\begin{array}{l}\text { Dressing in the mornings, using zippers and buttons, tying shoelaces, walking with high heeled shoes, choosing } \\
\text { and wearing shoes, wearing jackets, rings and watches }\end{array}$ & p230 p410 p440 p450 \\
\hline p550 & Eating & 2 & Opening packages and cans & $\mathrm{p} 445$ \\
\hline p560 & Drinking & 1 & Opening tops & p445 \\
\hline p570 & Looking after one's health & 17 & Handling medical side effects, planning medical intake, worries about gaining weight & p230 p450 p470 \\
\hline \multicolumn{5}{|c|}{ Domain 6:Domestic life } \\
\hline $\mathrm{p} 6$ & & 2 & Household chores & \\
\hline p610 & Acquiring a place to live & 0 & & \\
\hline p620 & Acquisition of goods and services & 19 & Shopping, acquiring firewood & p230 p415 p430 p440 p445 p450 p460 \\
\hline p630 & Preparing meals & 10 & $\begin{array}{l}\text { Cooking, cutting meat, peeling potatoes, baking, lifting heavy utensils, taking things out from the oven, open } \\
\text { cans. }\end{array}$ & $\mathrm{p} 415 \mathrm{p} 430 \mathrm{p} 440 \mathrm{p} 445 \mathrm{p} 450$ \\
\hline p640 & Doing housework & 22 & Laundry care, washing up the dishes, cleaning, vacuuming, washing windows, hanging curtains, ironing & p230 p410 p430 p440 p445 p450 p455 \\
\hline p650 & Caring for household objects & 37 & $\begin{array}{l}\text { Gardening, repairing houses, shovelling snow, changing exhaust tube, watering pot plants, sewing, assembling } \\
\text { or moving furniture, walking the dog, taking care of horses }\end{array}$ & $\begin{array}{l}\text { p4 p230 p410 p415 p430 p440 p445 p450 p540 } \\
\text { p570 }\end{array}$ \\
\hline p660 & Assisting others & 5 & $\begin{array}{l}\text { Helping an old mother take a shower, taking care of children, relatives or other people, lifting or run after } \\
\text { children outdoors. }\end{array}$ & p430 a455 \\
\hline \multicolumn{5}{|c|}{ Domain 7: Interpersonal interactions and relationships } \\
\hline p710 & Basic interpersonal interactions & 5 & Shaking hands, being embraced & \\
\hline p720 & Complex interpersonal interactions & 1 & Standing up after a long dinner with friends & $\mathrm{p} 410$ \\
\hline p730 & Relating with strangers & 1 & Taking RA into account when meeting unknown people, not showing symptoms & \\
\hline p740 & Formal relationships & 0 & & \\
\hline p750 & Informal social relationships & 8 & Having fewer guests at home, visiting fewer friends, more time spent at home resting & p230 p4 p415 p455 \\
\hline p760 & Family relationships & 26 & Socializing with grandchildren, taking care of children, socializing with the family and close relatives & $\begin{array}{l}\text { p230 p410 p415 p430 p435 p445 p455 p460 p475 } \\
\text { p530 p660 p710 }\end{array}$ \\
\hline p770 & Intimate relationships & 11 & Being dependent on husband in practical work, hugging with wife or husband, moving apart, sex life & p445 p650 p710 \\
\hline \multicolumn{5}{|c|}{ Domain 9: Community, social and civic life } \\
\hline p910 & Community life & 6 & Performing voluntary tasks in associations, reducing engagement in association life & p230 p430 p435 p440 p630 p710 p750 p920 \\
\hline p920 & Recreation and leisure & 67 & $\begin{array}{l}\text { Refraining from, reducing time for or adjusting the performance of recreation and leisure activities. Travelling, } \\
\text { dancing, watching show jumping, agility training with dogs, visiting swimming halls, fishing, hunting, } \\
\text { attending hockey matches. Play: playing computer games with children. Sports: walking, jogging, participating } \\
\text { in running races, playing golf, bowling, downhill skiing, playing soccer or bandy, physical training at gyms or } \\
\text { in classes. Arts and culture: going to the cinema, playing the trumpet. Socializing: being out with friends. }\end{array}$ & $\begin{array}{l}\text { p230 p240 p410 p415 p440 p445 p450 p465 p470 } \\
\text { p455 p540 p570 p650 p7 p750 p760 p770 }\end{array}$ \\
\hline p930 & Religion and spirituality & 1 & Socializing in the church & \\
\hline $\mathrm{p} 940$ & Human rights & 0 & & \\
\hline p950 & Political life and citizenship & 0 & & \\
\hline
\end{tabular}

